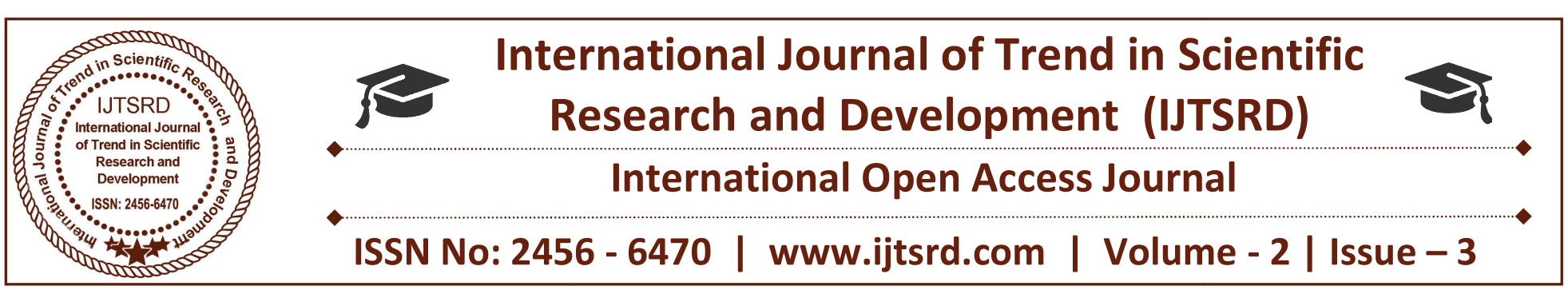

\title{
Adhesive from Petrol and Thermocol
}

\author{
Kaushal Harsola, Gautam Shelar, Manjusha Donde, Faisal Shaikh \\ Department of Civil Engineering, MET's Institute of Engineering, Nashik, Maharashtra, India
}

\section{INTRODUCTION}

In today's life the generation of plastic waste has become the serious issue. It causes serious health and ecological problems like breeding of mosquito's and if eaten by cattle and wild animals endangers their lives too, also it stops vegetation from growing and obstructs in drain and piping, etc. The consumption of plastic has reached to 100 million tons, and this has caused increase in depletion of natural resources such as petroleum and natural gas etc. About 13 percent of the municipal solid waste is caused by plastic. 32 million tons of plastic waste was deposited in 2011, which is 12.7 percent of total MSW. Annually approximately 500 billion plastic bags are used worldwide every year. More than 1 million bags are used every minute. The main aim of this project is to make useful product from waste thermocol i.e. adhesive.

Keywords: Thermocol, Petrol, plastic waste management, recycling of waste thermocol, Formation of structural Adhesive

\section{INTRODUCTION}

Generation of waste, garbage, trash, junk etc is depend on the type of material and places where they are used. It may consist of an unwanted or undesired material or substance left over from a manufacturing process (industrial, commercial) or from community and household activities. The waste material may collected, stored, or treated (physically, chemically, or biologically), prior to its disposal or recycled. Plastic is a synthetic material that is made by polymerizing molecules of monomer, materials that are derived from coal, petroleum or natural gas. Thus the recycling of plastic waste is must and also it reduces the accumulation of plastic in landfill. Basically there are four different ways of recycling of waste plastic and they are, primary recycling, secondary recycling, tertiary recycling (fuel and chemical recovery) and quaternary recycling (energy recovery). Combinations of these are well known and are used to some extent. The primary research of this paper is to develop an idea for re-utilizing waste plastic. Therefore by the mixing of petrol and Thermocol the chemical product is formed which acts as an adhesive and can be used in construction work. The adhesive could even stick two bricks, plywood, marbles, and metals together; using discarded plastic to make roads that are durable and environment friendly Adhesives are substances which are capable of holding materials together in a functional manner by surface attachment that resists separation. We use adhesives in our lives to a large extent.

\section{LITERATURE SURVEY}

\subsection{Definition of plastics}

Plastics are "one of the greatest innovations of modern life" and have certainly proved their reputation to be true. There are a numerous ways that plastic is and will be used in the years to come. The plastic has no effect of rusting or rottening, it is light in weight, low cost, reusable and conserves natural resources is the reason for which plastic has gained this much popularity. Again, Plastics save energy and $\mathrm{CO} 2$ emissions during their use phase. If we look from a life cycle perspective, then 22.4 million additional tons of crude oil per year would be required. Plastic covers a range of synthetic or semi synthetic polymerization products which can be moulded into any desired shape when subjected to heat and pressure. 


\subsection{Statistics of consumption of plastics and generation of plastics waste}

Continuous innovation explains that, plastics production has increased by an average of almost $10 \%$ every year on a global basis since 1950. The total global production of plastics has grown from around production of 245 million tonnes during 2006. An analysis of plastics consumption on a per capita 1.3 million tonnes (MT) in 1950 to 245 MT in 2006. The plastic consumption in some countries are summarised in Figure

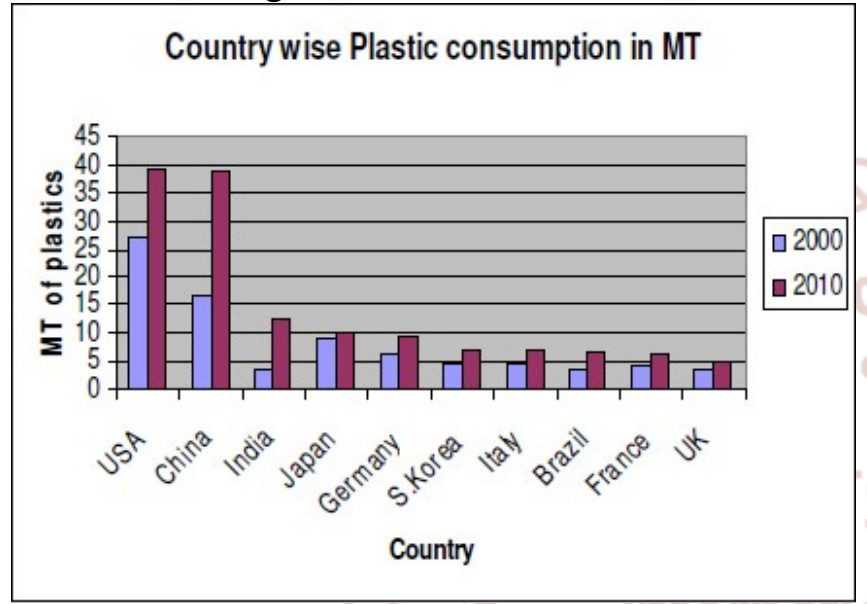

\section{METHODOLOGY}

\section{AIM:}

To prepare adhesives from petrol and thermocol.

\section{APPARATUS REQUIRED:}

Glass rod, Petrol/acetone, Thermocol, Beaker.

\section{CONDITIONS:}

The experiment was carried at normal room temperature and pressure.

\section{PROCEDURE:}

1) Take $50 \mathrm{ml}$ of petrol using a burette in a clean and dry glass beaker.

2) Now take the thermocol which has been cut into small pieces and add slowly to petrol in the beaker.

3) Stir continuously and keep on adding thermocol into the beaker.

4) After a while no more thermocol dissolves in the petrol.

5) Stop adding thermocol and allow it to stand for a few minutes.

6) After a while no more thermocol dissolves in the petrol or solvent, Stop adding thermocol and allow it to stand for a few minutes.

7) The beaker now has a thick and coagulated mass in it. This is the resultant adhesive.
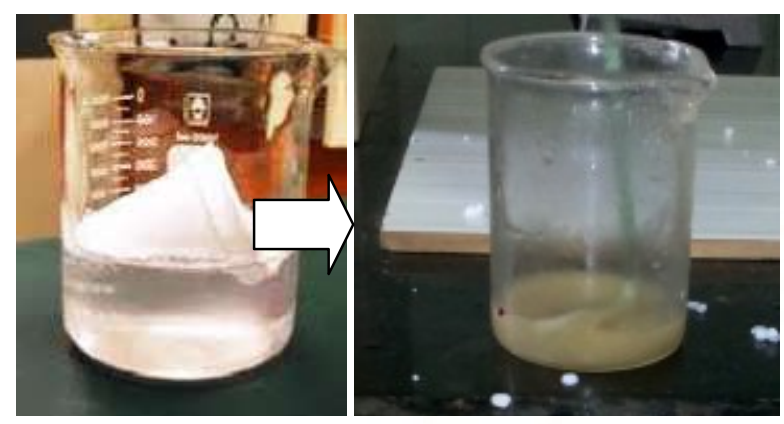

Fig. 1: Formation of Adhesive

\section{Samples of Experiment}

1) Sample of brick

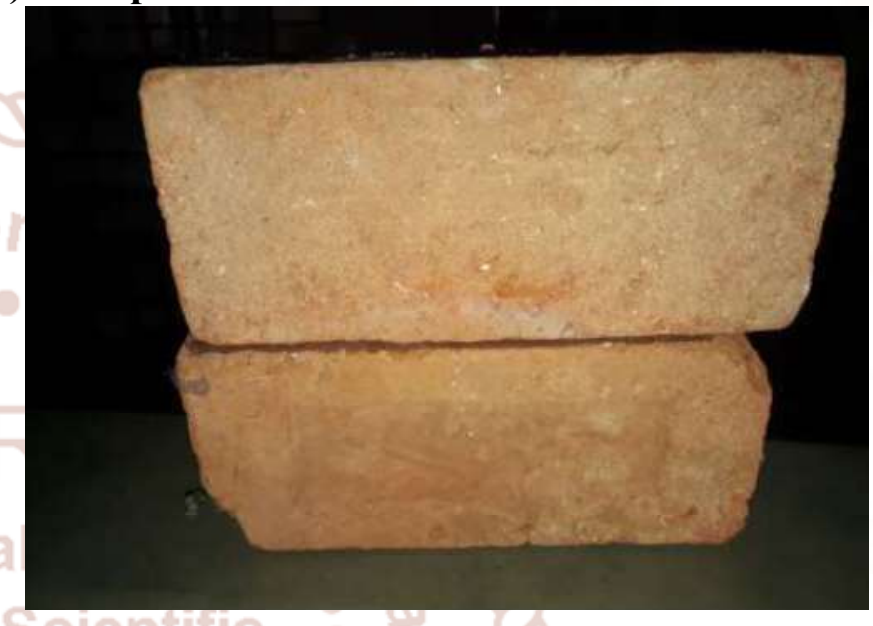

\section{2) Sample of concrete brick}

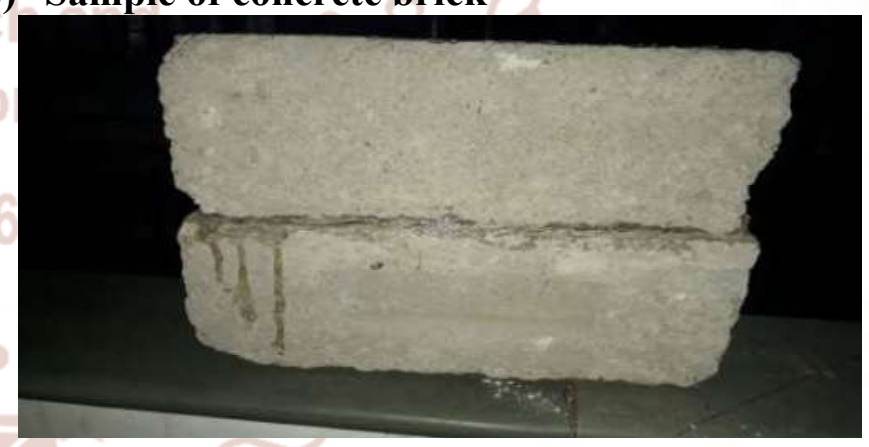

\section{3) Sample of marble}

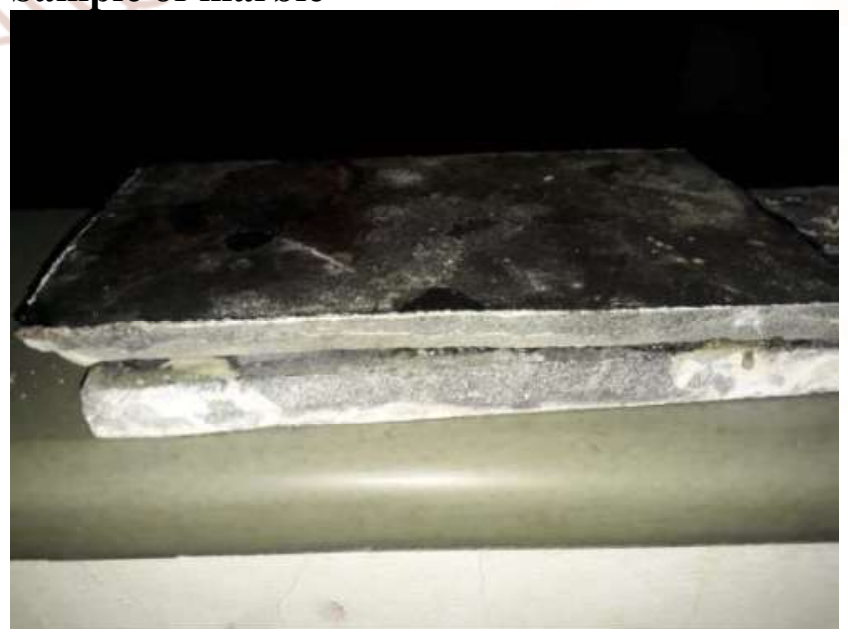




\section{OBJECIVES}

$>$ This project is an effort to overcome the problem generated by the wastage of Thermocol which affect the natural environmental aspect.

$>$ To prepare adhesives from waste Thermocol.

$>$ Using the adhesive in construction of walls and reducing the cost of binding material (cement paste).

$>$ Reducing the dead load of superstructure

$>$ To Reduced consumption of energy.

$>$ To Reduced amounts of solid waste going to landfill.

\section{IV.STATISTICAL ANALYSIS}

$>$ Volume of Thermocol consumed for 1liter of petrol $=50368.1 \mathrm{~cm}^{3}$

$>$ Adhesive obtain from 1 liter of petrol and $420 \mathrm{gm}$ of Thermocol is $=1.2 \mathrm{~kg}$

$>$ Surface area of 1 brick of $19 * 9 * 9=171 \mathrm{~cm}^{2}$

$>$ Amount of adhesive required for 1 one brick $=12.61 \mathrm{gm}$

$>$ Total no. of bricks covered with one liter of adhesive $=68$

$>$ Price of waste Thermocol $=40 \mathrm{Rs} / \mathrm{Kg}$

$>$ Price of petrol $=78.78 \mathrm{Rs} /$ Liter

\section{FUTURE SCOPE OF WORK}

$>$ To bring a change in construction techniques by implementing different construction materials.

$>$ Minimize the environmental pollution due to Thermocol.

$>$ Reduction the cost of construction of work by minimizing the use of cement and water.

\section{CONCLUSION AND FUTURE WORK}

The aim of this project is to prepare the adhesive from petrol and thermocol which can be used in construction work as an adhesive. The indirect benefits are, we can reuse the waste thermocol and the fuel required to burn the waste Thermocol and to control the environmental pollution up to certain extent.

Several lab tests where conducted on the final product (adhesive), so that it can be used safely in the construction work. We found that adhesive gives stronger bond cement paste, it resist the water up to some extent because of plastic thus it can be used as water proofing material if coated properly.
Due to plastic the adhesive gets fails in 'fire test' because plastic gets burn when it comes in contact with fire and hence it is found unsafe. Our future work is to found such product which could replace the petrol or can change the properties of plastic after formation of adhesive.

\section{REFERENCES}

1. https://timesofindia.indiatimes.com/city/pune/Stud ents-prepare-glue-from-thermocol-roads-fromplastic/articleshow/31124080.cms

2. Waste Thermocol to Adhesive for Better Environment by Narendra B. Selukar* Chaitanya V. Lande Chetankumar G. Ingole

3. https://sites.google.com/site/msgauthaman/prepara tionofadhesivefrompetrolandthermocole

4. A strategy towards the miscibility studies of Styrofoam in organic and inorganic ...by Muhammad Awais Farooqi (article june 2016)

5. http://saferenvironment.wordpress.com/2008/10/0 6/plastic-wastes---reduce-reuse-and-recycle-ofplastics-areessential-to-make-environmentgreener-and-safer//, 06-10-13, (2013).

6. http://www.ehow.com/how_12097412_makeglue-recycled-styrofoam.html

7. https://sites.google.com/site/msgauthaman/prepara

tionofadhesivefrompetrolandthermocole, 11-1113, (2012). 